\title{
Influence of ejaculation frequency on semen characteristics in chimpanzees (Pan troglodytes)*
}

\author{
J. Marson, D. Gervais, S. Meuris, R. W. Cooper and P. Jouannet $†$ \\ Centre International de Recherches Médicales de Franceville (CIRMF), BP 769, Franceville, \\ Gabon; and $\nmid$ Laboratoire d'histologie-embryologie, Centre Hospitalier Universitaire, \\ 94270 Le Kremlin Bicêtre, France
}

\begin{abstract}
Summary. Semen samples were obtained by masturbation from 6 chimpanzees and the spontaneously liquefied fraction and the remaining coagulum were studied separately. When semen was collected once or twice a week, large intra-individual variations were observed for all measures. The liquefied fraction represented $26 \cdot 5 \pm 3 \cdot 2 \%$ (weighted mean \pm s.d.) of the total ejaculate but contained $51 \cdot 3 \pm 3 \cdot 8 \%$ of all emitted spermatozoa. Fructose concentration was higher in the coagulum than in the liquefied fraction $(29.3 \pm 3.0 \mu \mathrm{mol} / \mathrm{ml}$ vs $12.0 \pm 2.7 \mu \mathrm{mol} / \mathrm{ml}, P<0.001)$ whereas acid phosphatase was less concentrated in the coagulum than in the liquefied fraction $\left(3.5 \pm 0.3 \times 10^{3} \mathrm{IU} / \mathrm{ml}\right.$ vs $\left.13.0 \pm 0.9 \times 10^{3} \mathrm{IU} / \mathrm{ml}, P<0.001\right)$. L-Carnitine and citrate concentrations did not differ between the two fractions of the ejaculate.

When semen collection was repeated every hour for $5 \mathrm{~h}$, the ejaculate volume increased from $2.6 \pm 0.7$ to $4.7 \pm 0.6 \mathrm{ml}(P<0.001)$, whereas total sperm count decreased from $1278 \pm 872 \times 10^{6}$ to $587 \pm 329 \times 10^{6}(P<0.05)$ between the 1 st and the 6th ejaculate. In the spontaneously liquefied fraction, the sperm count decreased from 984 to $369 \times 10^{6}$. The 6 successive ejaculates gave a total of $20.2 \pm 7.6 \mathrm{ml}$ and $4278 \pm 2884 \times 10^{6}$ spermatozoa. The increase of the ejaculate volume was essentially due to an increase of the volume of the coagulum which closely correlated with total amount of fructose (from seminal vesicles) $(r=0.913, P<0.001)$. The volume of the liquefied fraction and total amounts of L-carnitine (from epididymis), citrate and acid phosphatase (both from prostate) did not show any significant variations.

These results suggest (1) a high reserve capacity of the male genital tract in chimpanzees and (2) an increase in seminal vesicle secretion resulting from sexual stimulation induced by high masturbation frequency.
\end{abstract}

Keywords: semen; chimpanzee; ejaculation frequency; masturbation; fructose

\section{Introduction}

Chimpanzee semen coagulates upon emission but a spontaneous and partial liquefaction is obtained by incubation of the ejaculate at $37^{\circ} \mathrm{C}$ (Martin \& Gould, 1981; Marson et al., 1988). The remaining coagulum represents a limiting factor not only for sperm count, but also for the study of the biochemical substances secreted by the male accessory sex glands. So far, semen characteristics have been reported for the liquefied fraction alone (Warner et al., 1974), or for the total ejaculate after enzymic digestion (Roussel \& Austin, 1968; Ackerman \& Roussel, 1968).

Large intra-individual variations of semen characteristics have been observed in all species of primates examined (Martin \& Gould, 1981). In man, such variations are related in part to the

*Reprint requests to: Dr S. Meuris, Human Reproduction Research Unit, Hopital Saint Pierre, 322 Rue Haute, B-1000 Brussels, Belgium. 
length of sexual abstinence (Freund, 1962; Schwartz et al., 1979). The ejaculate volume and sperm count are inversely related to the frequency of ejaculation, increasing at low ejaculation frequency, decreasing at high frequency (Freund, 1962, 1963; Zimmerman et al., 1965; Mortimer et al., 1982; Levin et al., 1986).

The aims of the present study with chimpanzees were (1) to investigate the semen characteristics separately in the spontaneously liquefied fraction and in the remaining coagulum after enzymic digestion and (2) to analyse the effect of the masturbation frequency on semen characteristics.

\section{Materials and Methods}

Animals. Six wild-born chimpanzees, Pan troglodytes troglodytes, were studied for semen characteristics. All the animals had been at the Centre International de Recherches Médicales de Franceville (CIRMF) for more than 6 years and were housed in large enclosures in age- and size-matched social groups except for Chimpanzees MG and ED which were housed together. Age was estimated from regularly observed dental eruption (Nissen \& Riesen, 1945, 1964) and ranged from 10 to 16 years. During the study, body weight (BW) and left testicular volume (TV) were measured under anaesthesia as previously described (Marson et al., 1988). The 6 animals were, by chronological dental age: VA $\left(B W=48 \mathrm{~kg}, \mathrm{TV}=84 \mathrm{~cm}^{3}\right), \mathrm{NE}\left(\mathrm{BW}=56 \mathrm{~kg}, \mathrm{TV}=106 \mathrm{~cm}^{3}\right), \mathrm{PO}\left(\mathrm{BW}=50 \mathrm{~kg}, \mathrm{TV}=84 \mathrm{~cm}^{3}\right)$, $\mathrm{MG}\left(\mathrm{BW}=61 \mathrm{~kg}, \mathrm{TV}=109 \mathrm{~cm}^{3}\right), \mathrm{ED}\left(\mathrm{BW}=62 \mathrm{~kg}, \mathrm{TV}=95 \mathrm{~cm}^{3}\right)$ and $\mathrm{BN}\left(\mathrm{BW}=60 \mathrm{~kg}, \mathrm{TV}=60 \mathrm{~cm}^{3}\right)$.

Semen collection. The animals were masturbated by research workers as previously described (Marson et al., 1988). Semen was collected once or twice a week between 08:00 and 11:00 h. There was no possible control of the abstinence period between semen collections. To study the effect of high masturbation frequency on semen characteristics, hourly ejaculations were attempted starting at $08: 00 \mathrm{~h}$. Males NE and BN accepted this experiment which was repeated some days later. The number of ejaculates successively collected at $1-\mathrm{h}$ intervals varied from 4 to 6 samples.

Semen analysis. As semen coagulated totally upon emission, ejaculates were incubated for $1 \mathrm{~h}$ at $37^{\circ} \mathrm{C}$ to obtain partial liquefaction. The volume of the spontaneously liquefied fraction was measured with a graduated pipette. Dissolution of the coagulum was obtained by enzymic digestion with trypsin as previously described (Marson et al., 1988). The complete dissolution of the coagulum was obtained within $1 \mathrm{~h}$ of incubation at $37^{\circ} \mathrm{C}$. The volume of the coagulum was obtained by subtracting the volume of trypsin solution added from the total volume obtained after complete liquefaction.

As trypsin treatment interfered with sperm motility and vitality (Marson et al., 1988), these two variables were determined only in the spontaneously liquefied fraction. The percentage of motile spermatozoa was estimated by microscopic examination of a calibrated drop of $20 \mu \mathrm{l}$ semen placed under a $22 \times 32 \mathrm{~mm}$ coverslip $(\times 400)$. The percentage of live spermatozoa was determined according to the supravital staining method using eosin and nigrosin as described by Eliasson (1977).

Sperm counts were performed separately in the liquefied fraction and the trypsinized coagulum using a Thoma's haemocytometer.

Biochemical analysis of seminal plasma. When available, the remainder of each spontaneously liquefied fraction and trypsinized coagulum was centrifuged at $14000 \mathrm{~g}$ for $10 \mathrm{~min}$ at room temperature. The sperm-free supernatants were stored at $-60^{\circ} \mathrm{C}$ until assayed. L-Carnitine, fructose, citrate and acid phosphatase were determined in duplicate in the liquefied fraction and in the trypsinized coagulum. As trypsin did not interfere with these assays (Marson $e t$ al., 1988), these biochemical measures were made for both fractions of the ejaculate.

L-Carnitine, fructose and citrate were assayed in samples deproteinized by centrifugation for $20 \mathrm{~min}$ at $1000 \mathrm{~g}$ on CF 50 molecular filtration membranes (Amicon Corp., Danvers, MA, USA).

L-Carnitine was assayed according to the spectrophotometric method of Marquis \& Fritz (1964) as modified by Soufir et al. (1981). The modifications of absorbance were read at $405 \mathrm{~nm}$ during $30 \mathrm{~min}$ on a Pye Unicam Kinetics spectrophotometer (Philips, Cambridge, UK). The assays were conducted on undiluted deproteinized samples. The sensitivity of the assay was $20 \mathrm{nmol} / \mathrm{ml}$.

Fructose and citrate were assayed by specific enzymic methods (Bernt \& Bergmeyer, 1974; Dagley, 1974) using kits purchased from Boehringer (Mannheim, West Germany). The assays were conducted on samples diluted 1/10 in distilled water for fructose and undiluted for citrate. The sensitivity of both assays was $0.8 \mu \mathrm{mol} / \mathrm{ml}$.

The acid phosphatase activity was measured according to the colorimetric method based upon the inhibition of prostatic acid phosphatase by tartrate with p-nitrophenylphosphate (Sigma, St Louis, MO, USA) as the substrate (Method Sigma Bulletin No. 104). The assays were conducted at $405 \mathrm{~nm}$ on samples diluted $1 / 50000$ (for the liquefied fraction) or $1 / 10000$ (for the trypsinized coagulum) in distilled water.

Statistical analysis of results. Mean values were expressed \pm standard deviation ( \pm s.d.). Comparisons between means were made using analysis of the variance. Correlation coefficients and linear regressions were calculated using each individual value. 


\section{Results}

\section{Low ejaculation frequency}

At least 5 ejaculates were obtained by masturbation once or twice each week for each animal. Large intra-individual variations were observed for all semen variables (Table 1). The mean liquefied fraction represented about $27 \%$ of the total volume of the ejaculate and spermatozoa were significantly more concentrated in the liquefied fraction (weighted mean: $479 \pm 132 \times 10^{6} / \mathrm{ml}$, $n=6$ ) than in the coagulum (weighted mean: $174 \pm 41 \times 10^{6} / \mathrm{ml}, n=6, P<0.001$ ).

Table 1. Mean ( \pm s.d.) values and range (in parentheses) for semen characteristics of 6 subadult and adult chimpanzees

\begin{tabular}{lcccccc}
\hline & & & & \multicolumn{2}{c}{ In the liquefied fraction } \\
\cline { 5 - 7 } Animal & $\begin{array}{c}\text { Volume } \\
(\mathrm{ml})\end{array}$ & $\begin{array}{c}\text { Sperm count } \\
\left(10^{-6}\right)\end{array}$ & $\begin{array}{c}\text { \% of liquefaction } \\
\text { of the ejaculate }\end{array}$ & $\%$ of total sperm & $\%$ motility & $\%$ vitality \\
\hline VA & $2 \cdot 7 \pm 0 \cdot 9$ & $885 \pm 398$ & $35 \cdot 9 \pm 14 \cdot 0$ & $52 \cdot 4 \pm 14 \cdot 3$ & $51 \pm 13$ & $64 \pm 9$ \\
$(n=12)$ & $(1 \cdot 6-3 \cdot 7)$ & $(136-1488)$ & $(16 \cdot 2-62 \cdot 5)$ & $(27 \cdot 9-80 \cdot 9)$ & $(30-75)$ & $(53-86)$ \\
NE & $4 \cdot 4 \pm 1 \cdot 0$ & $2420 \pm 1165$ & $34 \cdot 9 \pm 7 \cdot 5$ & $75 \cdot 5 \pm 9 \cdot 8$ & $68 \pm 9$ & $75 \pm 9$ \\
$(n=14)$ & $(3 \cdot 0-5 \cdot 2)$ & $(1210-4957)$ & $(24 \cdot 7-50 \cdot 0)$ & $(58 \cdot 7-89 \cdot 2)$ & $(50-80)$ & $(53-85)$ \\
PO & $3 \cdot 9 \pm 0 \cdot 8$ & $1182 \pm 523$ & $21 \cdot 4 \pm 11 \cdot 7$ & $61 \cdot 9 \pm 20 \cdot 6$ & $75 \pm 11$ & $83 \pm 7$ \\
$(n=19)$ & $(2 \cdot 7-4 \cdot 9)$ & $(180-2047)$ & $(8 \cdot 0-45 \cdot 2)$ & $(19 \cdot 8-96 \cdot 6)$ & $(45-85)$ & $(67-91)$ \\
MG & $3 \cdot 0 \pm 0 \cdot 7$ & $847 \pm 466$ & $20 \cdot 4 \pm 9 \cdot 3$ & $38 \cdot 0 \pm 16 \cdot 0$ & $57 \pm 18$ & $75 \pm 8$ \\
$(n=8)$ & $(1 \cdot 9-3 \cdot 8)$ & $(446-1842)$ & $(6 \cdot 6-31 \cdot 8)$ & $(17 \cdot 0-57 \cdot 7)$ & $(30-75)$ & $(62-87)$ \\
ED & $4 \cdot 0 \pm 0 \cdot 6$ & $1224 \pm 766$ & $21 \cdot 6 \pm 4 \cdot 7$ & $45 \cdot 7 \pm 4 \cdot 8$ & $40 \pm 7$ & $62 \pm 4$ \\
$(n=5)$ & $(3 \cdot 2-4 \cdot 7)$ & $(300-2276)$ & $(15 \cdot 0-25 \cdot 6)$ & $(39 \cdot 6-50 \cdot 7)$ & $(30-50)$ & $(59-68)$ \\
BN & $2 \cdot 3 \pm 0 \cdot 4$ & $579 \pm 218$ & $41 \cdot 8 \pm 10 \cdot 6$ & $54 \cdot 2 \pm 15 \cdot 1$ & $53 \pm 13$ & $61 \pm 11$ \\
$(n=10)$ & $(1 \cdot 4-2 \cdot 9)$ & $(286-861)$ & $(25 \cdot 5-76 \cdot 5)$ & $(32 \cdot 5-76 \cdot 5)$ & $(25-70)$ & $(34-76)$ \\
Mean $\dagger$ & $3 \cdot 5 \pm 0 \cdot 3$ & $784 \pm 162$ & $26 \cdot 5 \pm 3 \cdot 2$ & $51 \cdot 3 \pm 3 \cdot 8$ & $55 \pm 4$ & $68 \pm 3$ \\
$(n=6)$ & & & & & & \\
\hline
\end{tabular}

$n=$ Number of ejaculates/animal.

† Weighted means.

The seminal plasma of 4 of the 6 animals was analysed biochemically. The mean concentration of fructose was significantly higher in the coagulum than in the liquefied fraction whereas acid phosphatase was more concentrated in the liquefield fraction (Table 2). The mean concentrations of citrate and L-carnitine did not significantly differ between the two fractions of the ejaculate. In the total ejaculate, the weighted mean concentrations of L-carnitine, fructose, citrate and acid phosphatase were $1226 \pm 191 \mathrm{nmol} / \mathrm{ml}, 22.0 \pm 6.0 \mu \mathrm{mol} / \mathrm{ml}, 4 \cdot 0 \pm 0.7 \mu \mathrm{mol} / \mathrm{ml}$ and $5926 \pm 910 \mathrm{IU} / \mathrm{ml}$, respectively.

When considering all ejaculates, the volume of the coagulum was significantly correlated with total amount of fructose (Table 3). The volume of the liquefied fraction was correlated with total amounts of L-carnitine, citrate and acid phosphatase. The percentage of liquefaction of the ejaculate was positively correlated with citrate and acid phosphatase concentrations $(r=0 \cdot 711$, $P<0.001$ and $r=0.793, P<0.001$, respectively) but was negatively correlated with fructose concentration $(r=-0.587, P<0.001)$.

Total amount of $\mathrm{L}$-carnitine was correlated with total sperm count $(r=0.813, P<0.001)$, total citrate $(r=0.836, P<0.001)$ and total acid phosphatase $(r=0.631, P<0.001)$. Total amounts of citrate and total acid phosphatase were correlated $(r=0.784, P<0.001)$. 
Table 2. Mean ( \pm s.d.) volume and concentrations for L-carnitine, fructose, citrate and acid phosphatase for the spontaneously liquefied fraction and the coagulum of Chimpanzees NE, PO, MG and BN

\begin{tabular}{|c|c|c|c|c|c|}
\hline & $\begin{array}{c}\mathrm{NE} \\
(n=10)\end{array}$ & $\begin{array}{c}\text { PO } \\
(n=7)\end{array}$ & $\begin{array}{c}\text { MG } \\
(n=4)\end{array}$ & $\begin{array}{c}\text { BN } \\
(n=9)\end{array}$ & $\begin{array}{l}\text { Mean } \dagger \\
(n=4)\end{array}$ \\
\hline \multicolumn{6}{|l|}{ Liquefied fraction } \\
\hline Volume (mI) & $1.57 \pm 0.38$ & $0.66 \pm 0.16$ & $0.70 \pm 0.32$ & $0.84 \pm 0.51$ & $0.78 \pm 0.13$ \\
\hline Carnitine $(\mathrm{nmol} / \mathrm{ml})$ & $3382 \pm 1197$ & $1270 \pm 477$ & $1043 \pm 488$ & $3235 \pm 1768$ & $1389 \pm 322$ \\
\hline Fructose $(\mu \mathrm{mol} / \mathrm{ml})$ & $11.5 \pm 11.0$ & $11.6 \pm 6.0$ & $13.9 \pm 7.4$ & $11.8 \pm 3.6$ & $12.0 \pm 2.7$ \\
\hline Citrate $(\mu \mathrm{mol} / \mathrm{ml})$ & $10.4 \pm 2.0$ & $3.1 \pm 1.3$ & $4.5 \pm 2.6$ & $11.5 \pm 7.4$ & $5.3 \pm 0.9$ \\
\hline Acid phosphatase $(\mathrm{IU} / \mathrm{ml})$ & $16.0 \pm 3.6$ & $13.2 \pm 2.8$ & $11.7 \pm 1.1$ & $27.8 \pm 4.2$ & $13.0 \pm 0.9$ \\
\hline \multicolumn{6}{|l|}{ Coagulum } \\
\hline Volume (ml) & $3.35 \pm 0.70$ & $3.17 \pm 0.82$ & $2.40 \pm 0.75$ & $1.84 \pm 1.07$ & $2.82 \pm 0.40$ \\
\hline Carnitine $(\mathrm{nmol} / \mathrm{ml})$ & $2481 \pm 885$ & $600 \pm 416$ & $1121 \pm 262$ & $1914 \pm 840$ & $1114 \pm 208$ \\
\hline Fructose $(\mu \mathrm{mol} / \mathrm{ml})$ & $23.4 \pm 17.0$ & $32 \cdot 7 \pm 4 \cdot 1$ & $30.6 \pm 7.0$ & $20.8 \pm 6.4$ & $29 \cdot 3 \pm 3 \cdot 0^{* *}$ \\
\hline Citrate $(\mu \mathrm{mol} / \mathrm{ml})$ & $7.4 \pm 3.3$ & $2.8 \pm 0.9$ & $4.8 \pm 1.2$ & $7.7 \pm 3.6$ & $3.8 \pm 0.7$ \\
\hline Acid phosphatase (IU/ml) & $5.0 \pm 2 \cdot 1$ & $3.2 \pm 1.7$ & $3.4 \pm 0.3$ & $9 \cdot 3 \pm 3 \cdot 0$ & $3.5 \pm 0.3^{* *}$ \\
\hline
\end{tabular}

$n=$ Number of samples/animal.

+Weighted means.

$* * P<0.001$ compared with value for liquefied fraction.

Table 3. Correlations between the volume of the liquefied and coagulated fractions of the ejaculate and total amounts of the biochemical parameters at low and high ejaculation frequency

\begin{tabular}{llllll}
\hline & \multicolumn{2}{c}{ Liquefied fraction } & & \multicolumn{2}{c}{ Coagulum } \\
\cline { 2 - 3 } \cline { 5 - 6 } \cline { 5 - 6 } & Low & High & & Low & High \\
\hline L-Carnitine & $0 \cdot 746^{* *}$ & $0.764^{* *}$ & & 0.341 & 0.422 \\
Fructose & 0.325 & 0.315 & & $0.880^{* *}$ & $0.913^{* *}$ \\
Citrate & $0.817^{* *}$ & $0.722^{* *}$ & & $0 \cdot 184$ & 0.050 \\
Acid phosphatase & $0.780^{* *}$ & $0.764^{* *}$ & & 0.072 & 0.435 \\
\hline
\end{tabular}

**P $<0.001$.

\section{High ejaculation frequency}

The mean volume of the total ejaculate increased progressively with the 6 successive ejaculates collected hourly: from $2.6 \pm 0.7$ to $4.7 \pm 0.6 \mathrm{ml}(y=2.6+0.42 x, r=0.797, P<0.001)$. The volume of the liquefied fraction remained constant (Fig. 1) while the volume of the coagulum increased significantly $(y=1.9+0.41 x, r=0.751, P<0.001)$. The volume of the coagulum was correlated with total ejaculate volume $(r=0.945, P<0.001)$. Mean sperm count decreased significantly between the 1 st and the 6 th ejaculate from $1278 \pm 872 \times 10^{6}$ to $587 \pm 329 \times 10^{6}$ $(y=1090-144 x, r=-0.420, P<0.05$ ) (Fig. 1). In the liquefied fraction, the sperm count decreased from $984 \pm 928 \times 10^{6}$ to $369 \pm 328 \times 10^{6}$. This decrease was not significant. Spermatozoa were always more concentrated in the liquefied fraction which contained $42 \cdot 3 \pm 24 \cdot 3 \%$ of the total sperm count. A total of $20.2 \pm 7.6 \mathrm{ml}$ and $4278 \pm 2884 \times 10^{6}$ spermatozoa was emitted in $5 \mathrm{~h}$.

Mean percentages of motility and vitality of spermatozoa did not show any significant variations from the first to the last ejaculate and were always above 50 and $65 \%$, respectively.

Total amount of fructose increased significantly between the first and the last ejaculate $(y=38.3+22.0 x, r=0.836, P<0.001)$ (Fig. 1) and was significantly correlated with the volume of the coagulum (Table 3 ). Total amounts of L-carnitine, citrate and acid phosphatase did not show 

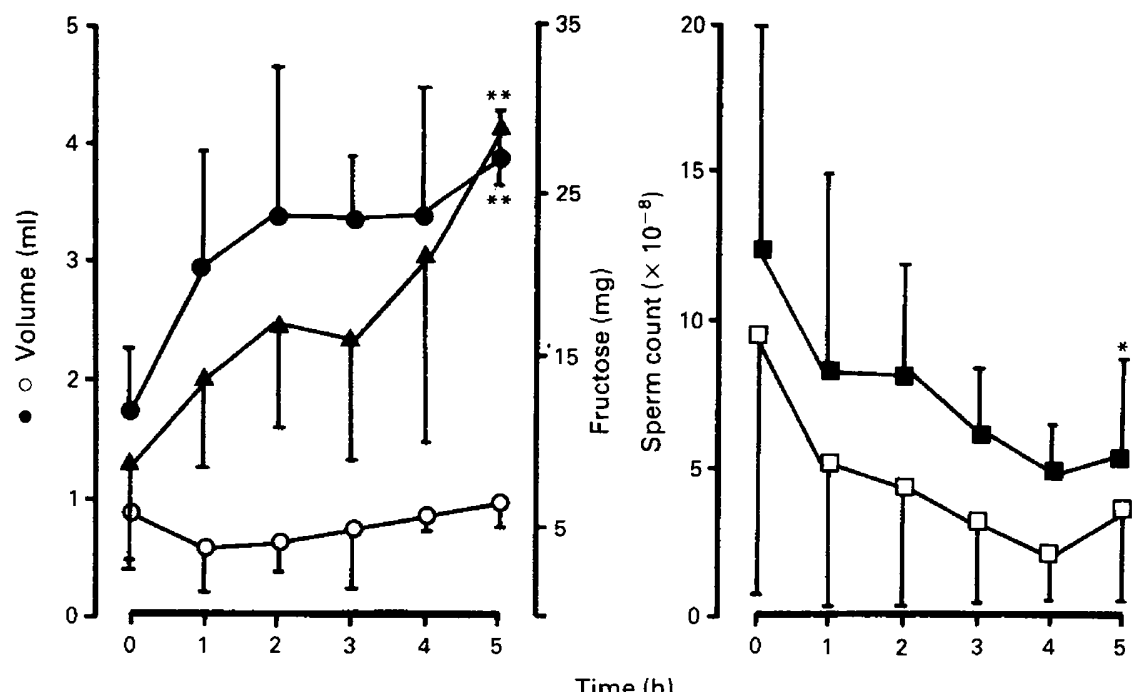

Fig. 1. Effect of repeated ejaculation (every hour) on the volume of the liquefied $(\mathrm{O}-\mathrm{O})$ and coagulated fractions $(-\mathbf{O})$, on total fructose $(\boldsymbol{\Delta}-\mathbf{\Lambda})$ and on total sperm count in the total ejaculate ( $\square-\square)$ and in the liquefied fraction ( $\square-\square$ ) of chimpanzees. Values are mean \pm s.d. ${ }^{*} P<0.05,{ }^{* *} P<0.001$ compared with value at $0 \mathrm{~h}$ (analysis of regression).

Table 4. Effect of repeated ejaculation on concentrations and total amounts of L-carnitine, fructose, citrate and acid phosphatase in the total ejaculate of chimpanzees

\begin{tabular}{|c|c|c|c|c|}
\hline $\begin{array}{l}\text { Time } \\
\text { (h) }\end{array}$ & $\begin{array}{l}\text { L-Carnitine } \\
(\mathrm{nmol})\end{array}$ & $\begin{array}{c}\text { Fructose } \\
(\mu \mathrm{mol})\end{array}$ & $\begin{array}{l}\text { Citrate } \\
(\mu \mathrm{mol})\end{array}$ & $\begin{array}{l}\text { Acid phosphatase } \\
\text { (IU) }\end{array}$ \\
\hline \multicolumn{5}{|l|}{$0(n=4)$} \\
\hline $\begin{array}{l}\text { Per ml } \\
\text { Total }\end{array}$ & $\begin{array}{l}2681 \pm 621 \\
6990 \pm 2781\end{array}$ & $\begin{array}{l}14 \cdot 0 \pm 4 \cdot 5 \\
35 \cdot 5 \pm 11 \cdot 1\end{array}$ & $\begin{array}{r}7 \cdot 4 \pm 3 \cdot 0 \\
26 \cdot 0 \pm 12 \cdot 5\end{array}$ & $\begin{array}{l}11492 \pm 3579 \\
28648 \pm 9072\end{array}$ \\
\hline \multicolumn{5}{|l|}{$1(n=4)$} \\
\hline $\begin{array}{l}\text { Per ml } \\
\text { Total }\end{array}$ & $\begin{array}{l}2124 \pm 614 \\
6722 \pm 3022\end{array}$ & $\begin{array}{l}23 \cdot 4 \pm 4 \cdot 0 \\
66 \cdot 6 \pm 14 \cdot 4\end{array}$ & $\begin{array}{r}7 \cdot 4 \pm 1 \cdot 0 \\
23 \cdot 4 \pm 7 \cdot 8\end{array}$ & $\begin{array}{r}8466 \pm 2172 \\
26933 \pm 11034\end{array}$ \\
\hline \multicolumn{5}{|l|}{$2(n=4)$} \\
\hline Per ml & $1977 \pm 550$ & $22.9 \pm 1.5$ & $5 \cdot 1 \pm 1 \cdot 0$ & $7103 \pm 2328$ \\
\hline Total & $7340 \pm 2682$ & $84 \cdot 4 \pm 22 \cdot 2$ & $19 \cdot 3 \pm 8 \cdot 3$ & $27158 \pm 15678$ \\
\hline \multicolumn{5}{|l|}{$3(n=4)$} \\
\hline Per ml & $1659 \pm 512$ & $22 \cdot 6 \pm 3 \cdot 3$ & $4 \cdot 0 \pm 0.8$ & $5531 \pm 2794$ \\
\hline Total & $6724 \pm 2568$ & $93.2 \pm 33 \cdot 3$ & $16 \cdot 1 \pm 4 \cdot 6$ & $23976 \pm 16091$ \\
\hline \multicolumn{5}{|l|}{$4(n=3)$} \\
\hline Per ml & $1458 \pm 318$ & $29 \cdot 5 \pm 5 \cdot 0$ & $4 \cdot 8 \pm 1 \cdot 6$ & $6121 \pm 996$ \\
\hline Total & $6433 \pm 1512$ & $134.9 \pm 46.0$ & $20 \cdot 3 \pm 2 \cdot 6$ & $27174 \pm 6091$ \\
\hline \multicolumn{5}{|l|}{$5(n=3)$} \\
\hline Per ml & $1582 \pm 642^{*}$ & $31 \cdot 5 \pm 2 \cdot 5^{* *}$ & $4 \cdot 5 \pm 1 \cdot 0^{* *}$ & $5808 \pm 849^{*}$ \\
\hline Total & $7483 \pm 3252$ & $147 \cdot 6 \pm 27 \cdot 7^{* *}$ & $20 \cdot 8 \pm 3 \cdot 6$ & $27421 \pm 7468$ \\
\hline
\end{tabular}

Values are mean \pm s.d. for the no. of samples indicated $(n)$.

${ }^{*} P<0.05,{ }^{* *} P<0.001 \mathrm{vs}$ mean values at $0 \mathrm{~h}$ (analysis of regression).

any significant variations (Table 4). The significant correlations previously observed between the volume of the liquefied fraction and total amounts of $\mathrm{L}$-carnitine, citrate and acid phosphatase were also observed at high ejaculation frequency (Table 3 ). 
The concentration of fructose increased $(y=16.5+3.0 x, r=0.785, P<0.001)$, while the concentrations of L-carnitine, citrate and acid phosphatase decreased $(y=2485-213 x$, $r=-0.609, \quad P<0.05 ; \quad y=8.5-1.0 x, \quad r=-0.696, \quad P<0.001$ and $y=10144-1117 x$, $r=-0.625, P<0.05$, respectively) (Table 4). Fructose was always more concentrated in the coagulum (weighted means: $21.6 \pm 3.1 \mu \mathrm{mol} / \mathrm{ml}$ vs $13.5 \pm 3.4 \mu \mathrm{mol} / \mathrm{ml}, P<0.001$ ) and acid phosphatase in the liquefied fraction (weighted means: $15.5 \pm 1.9 \times 10^{3}$ vs $5 \cdot 1 \pm 0.6 \times 10^{3} \mathrm{IU} / \mathrm{ml}$, $P<0.001$ ). As observed at low ejaculation frequency, the percentage liquefaction of the ejaculate was positively correlated with citrate and acid phosphatase concentrations $(r=0.786, P<0.001$ and $r=0.690, P<0.01$, respectively) and negatively correlated with fructose concentration $(r=-0.540, P<0.05)$.

\section{Discussion}

Total ejaculate volume and total sperm counts were higher than those reported in earlier studies using electroejaculation (Ackermann \& Roussel, 1968; Roussel \& Austin, 1968; Warner et al., 1974; Gould, 1983) but similar to those observed for semen samples obtained by masturbation (Bader, 1983; Marson et al., 1988). In the present study, the analysis of the liquefied fraction and of the coagulum separately showed that the mean volume of the liquefield fraction represented $27 \%$ of the total ejaculate but contained $51 \%$ of the total sperm count. Moreover, the liquefied fraction contained less fructose and more acid phosphatase than did the coagulum whereas L-carnitine and citrate concentrations did not differ between these two fractions of the ejaculate.

The close correlation observed between L-carnitine and sperm count suggests that, in chimpanzee, L-carnitine is mainly produced by the epididymis, as in man (Soufir et al., 1981). Correlations between total amounts (or concentrations) of L-carnitine and citrate and acid phosphatase have been previously described in human (Soufir et al., 1982), but remained unexplained. In the chimpanzee, as in man, fructose and acid phosphatase are considered to be specific markers of the seminal vesicles and the prostate, respectively (Mann \& Lutwak-Mann, 1981; Martin \& Gould, 1981). In the present study, citrate was closely correlated with acid phosphatase but not with fructose. This suggests a prostatic origin of citrate in chimpanzee, as in man (Mann \& Lutwak-Mann, 1981).

In man, the coagulation of the semen is induced by the secretory products of the seminal vesicles: when the vas deferens and seminal vesicles are congenitally absent, there is no evidence of coagulation of the semen (Amelar, 1962). On the other hand, the liquefaction process is induced by factor(s) contained in the first portion of a split ejaculate consisting mainly of prostatic secretion (Tauber et al., 1980). In the present study, the percentage of liquefaction of the ejaculate was positively correlated with citrate and acid phosphatase concentrations, of prostatic origin, but negatively correlated with concentration of fructose, from seminal vesicles. These results suggest that, in the chimpanzee as in man, the coagulation-liquefaction process depends on a balance between seminal and prostatic secretions.

In man, the ejaculate volume decreases as the interval between ejaculations decreases (McLeod \& Gold, 1952; Lampe \& Masters, 1956; Freund, 1962, 1963; Eliasson, 1965; Van Duijn \& Freund, 1971; Mortimer et al., 1982; Rui et al., 1984). In the present study, sexual abstinence was neither controlled nor monitored. The animals had the opportunity to copulate and/or to masturbate freely. The large intra-individual variations of semen values observed may be related in part to the sexual abstinence period, as in man (Schwartz et al., 1979; Jouannet et al., 1981).

In the experiment with high ejaculation frequency, the ejaculate volume increased gradually and a total of $20.2 \mathrm{ml}$ could be emitted in 6 successive ejaculates. The increase of the ejaculate volume was associated with an increase of the coagulated fraction and not of the liquefied one. The volume of the coagulum was closely correlated with total amount of fructose but not with any other biochemical marker. The coagulum may, therefore, represent mainly the secretion of the seminal vesicles. The gradual increase of the ejaculate volume probably reflects a progressive increase in the 
secretion of seminal vesicles while the prostatic and epididymal secretions remain constant. These results indicate a high reserve capacity of the male genital tract (particularly of the seminal vesicles) in the chimpanzee and probably a high rate of production of seminal plasma.

The progressive increase of the ejaculate volume at high ejaculation frequency may be related to the degree of sexual excitation. In dairy bulls, the degree of sexual excitation, increased by 'falsemounts' before semen collection, has a positive effect on semen volume and sperm count (Freund, 1963). In man, semen samples collected by masturbation may not represent those delivered during normal intercourse (Tyler et al., 1983; J. P. Tyler \& N. G. Crockett, unpublished). The degree of sexual stimulation may therefore influence the magnitude of depletion of the male genital tract during ejaculation. In chimpanzee, this concerns particularly the seminal vesicles.

When semen collection was repeated every hour, the total sperm count decreased progressively between the first and the last ejaculate. In the liquefied fraction, the decrease of the number of freely available spermatozoa was not significant. A total of $4300 \times 10^{6}$ spermatozoa could be emitted and, even after the 6th ejaculation, the epididymal sperm reserves were not completely depleted. This large reserve capacity of the epididymis may have advantages in the multi-male breeding system of chimpanzees in which each male mates frequently with the oestrous females and has to deposit enough spermatozoa to compete with those of other males (Harcourt et al., 1981; Martin \& May, 1981; Quiatt \& Everett, 1982). Despite modifications of the biochemical characteristics of the liquefied semen fraction that could perhaps affect sperm motility or vitality, we did not observe any significant variations in the percentages of motile and live spermatozoa. The characteristics of the movement pattern and the in-vitro fertilizing ability of spermatozoa from the different samples collected should be studied.

Dr S. Meuris is presently research associate from the National Fund of Scientific Research (Belgium).

\section{References}

Ackerman, D.R. \& Roussel, J.D. (1968) Fructose, lactic acid and citric acid content of the semen of eleven subhuman primates species and of man. $J$. Reprod. Fert. 17, 563-566.

Amelar, R.D. (1962) Coagulation, liquefaction and viscosity of human semen. $J$. Urol. 87, 187-190.

Bader, H. (1983) Electroejaculation in chimpanzees and gorillas and artificial insemination in chimpanzees. Zoo Biol. 2, 307-314.

Bernt, E. \& Bergmeyer, H.U. (1974) D-fructose. In Methods of Enzymatic Analysis, pp. 1303-1307. Ed. H. U. Bergmeyer. Verlag Chemie, New York.

Dagley, S. (1974) Citrate UV spectrophotometric determination. In Methods of Enzymatic Analysis, pp. 1562-1565. Ed. H. U. Bermeyer. Verlag Chemie, New York.

Eliasson, R. (1965) Effect of frequent ejaculations on the composition of seminal plasma. J. Reprod. Fert. 9, 331-336.

Eliasson, R. (1977) Supravital staining of human spermatozoa. Fert. Steril. 28, 1257.

Freund, M. (1962) Interrelationships among characteristics of human semen and factors affecting semenspecimen quality. J. Reprod. Fert. 4, 143-159.

Freund, M. (1963) Effect of frequency of emission on semen output and estimate of daily sperm production in man. J. Reprod. Fert. 6, 269-286.

Gould, K. G. (1983) Diagnosis and treatment of infertility in male great apes. Zoo Biol. 2, 281-293.
Harcourt, A.H., Harvey, P.H., Larson, S.G. \& Short, R.V. (1981) Testis weight, body weight and breeding system in primates. Nature, Lond. 23, 55-57.

Jouannet, P., Czyglik, F., David, G., Mayaux, M. J., Spira, A., Moscato, M.L. \& Schwartz, D. (1981) Study of a group of 484 fertile men. Part I: Distribution of semen characteristics. Int. J. Androl. 4, $440-449$.

Lampe, E.H. \& Masters, W.H. (1956) Problems of male fertility. II. Effect of frequent ejaculation. Fert. Steril. 7, 123-127.

Levin, R.M., Latimore, J., Wein, A.J. \& Van Arsdalen, K.N. (1986) Correlation of sperm count with frequency of ejaculation. Fert. Steril. 45, 732-734.

Mann, T. \& Lutwak-Mann, C. (1981) Male Reproductive Function and Semen. Springer-Verlag, New York.

Marquis, N.R.P. \& Fritz, I.B. (1964) Enzymological determination of free carnitine concentrations in rat tissues. J. Lipid Res. 5, 184-187.

Marson, J., Meuris, S., Moysan, F., Gervais, D., Cooper, R.W. \& Jouannet, P. (1988) Cellular and biochemical characteristics of semen obtained from pubertal chimpanzees by masturbation. J. Reprod. Fert. 82, 199-207.

Martin, D.E. \& Gould, K.G. (1981) The male ape genital tract and its secretions. In Reproductive Biology of the Great Apes. Comparative and Biomedical Perspectives, pp. 127-162. Ed. C. E. Graham. Academic Press, New York. 
Martin, R.D. \& May, R.M. (1981) Outward signs of breeding. Nature, Lond. 293, 7-9.

McLeod, J. \& Gold, R.Z. (1952) The male factor in fertility and infertility. V. Effect of continence on semen quality. Fert. Steril. 3, 297-315.

Mortimer, D., Templeton, A.A., Lenton, E.A. \& Coleman, R.A. (1982) Influence of abstinence and ejaculationto-analysis delay on semen analysis parameters of suspected infertile men. Archs Androl. 8, 251-256.

Nissen, H.W. \& Riesen, A.H. (1945) The deciduous dentition of chimpanzee. Growth 9, 265-274.

Nissen, H.W. \& Riesen, A.H. (1964) The eruption of the permanent dentition of chimpanzee. Am. J. phys. Anthrop. 22, 285-294.

Quiatt, D. \& Everett, J. (1982) How can sperm competition work? Am. J. Primatol., Suppl. 1, $161-169$.

Roussel, J.D. \& Austin, C.R. (1968) Improved electroejaculation of primates, J. Inst. Anim. Tech. 19, 22-32.

Rui, H., Gerhardt, P., Mevag, B., Thomassen, Y. \& Purvis, K. (1984) Seminal plasma characteristics during frequent ejaculation. Int. J. Androl. 7, 119-128.

Schwartz, D., Laplanche, A., Jouannet, P. \& David, G. (1979) Within-subject variability of human semen in regard to sperm count, volume, total number of spermatozoa and length of abstinence. $J$. Reprod. Fert. 57, 391-395.

Soufir, J.C., Marson, J. \& Jouannet, P. (1981) Free L-carnitine in human seminal plasma. Int. J. Androl. 4, 388-397.

Soufir, J.C., Marson, J. \& Ducot, B. (1982) L-carnitine séminale chez les sujets féconds et inféconds. In Les Facteurs de la Fertilité humaine, pp. 127-131. Eds A. Spira \& P. Jouannet. INSERM, Paris.

Tauber, P.F., Propping, D., Schumacher, G.F.B. \& Zaneveld, L.J.D. (1980) Biochemical aspects of the coagulation and liquefaction of human semen. $J$. Androl. 1, 280-288.

Tyler, J.P.P., Crockett, N.G. \& Driscoll, G.L. (1983) How representative are semen samples? Lancet 1,191 .

Van Duijn, G. \& Freund, M. (1971) The relationship between some seminal characteristics and ejaculation frequency in the human male. Eur. J. Obstet. Gynaec. 5, 167-174.

Warner, H., Martin, D.E. \& Keeling, M.E. (1974) Electroejaculation of the great apes. Annls biomed. Eng. 2, 419-432.

Zimmerman, S.J., Maude, M.B. \& Moldawer, M. (1965) Frequent ejaculation and total sperm count, motility and forms in humans. Fert. Steril. 16, 342-345.

Received 7 March 1988 